\title{
The Market Timing Skills of Hedge Funds during the Financial Crisis*
}

\author{
Arnaud CAVÉ \\ Georges HÜBNER ${ }^{\ddagger}$ \\ Danielle SOUGNÉ§
}

May 2011

\begin{abstract}
The performance of a market timer can be measured through the Treynor and Mazuy (1966) model, provided the regression alpha is properly adjusted by using the cost of an option-based replicating portfolio, as shown by Hübner (2010). We adapt this approach to the case of multifactor models with positive, negative or neutral betas.

This new approach is applied on a sample of hedge funds whose managers are likely to exhibit market timing skills. We stick to funds that post weekly returns, and analyze three hedge funds strategies in particular: long-short equity, managed futures, and funds of hedge funds. We analyse a particular period during which the managers of these funds are likely to magnify their presumed skills, namely around the financial and banking crisis of 2008 .

Some funds adopt a positive convexity as a response to the US market index, while others have a concave sensitivity to the returns of an emerging market index. Thus, we identify "positive", "mixed" and "negative" market timers. A number of signs indicate that only positive market timers manage to acquire options below their cost, and deliver economic significant performance, even in the midst ot the financial crisis. Negative market timers, by contrast, behave as if they were forced to sell options without getting the associated premium. We interpret this behavior as a possible result of fire sales, leading them to liquidate positions under the pressure of redemption orders, and inducing negative performance adjusted for market timing.

Keywords: Performance measurement, market timing, Treynor and Mazuy, option replication, hedge fund performance.
\end{abstract}

JEL codes: G10, G12

\footnotetext{
*This paper has benefitted from comments by Guillaume Monarcha and Bertrand Maillet, as well as the 2011 Thematic Cluster Day on Hedge Funds from the University of Orleans attendees. Georges Hübner acknowledges financial support of Deloitte Belgium and Deloitte Luxembourg. Danielle Sougné acknowledges financial support of KBL European Private Bankers. All remaining errors are ours.

${ }^{\dagger}$ University of Liège, HEC Management School, Department of Finance. E-mail: A.Cave@ulg.ac.be.

${ }^{\ddagger}$ The Deloitte Chair of Portfolio Management and Performance, HEC Management School - University of Liège, Belgium; Associate Professor, School of Economics and Business, Maastricht University, the Netherlands; Founder \& Chief Scientific Officer, Gambit Financial Solutions Ltd, Belgium. Corresponding author. University of Liège, HEC Management School, Rue Louvrex 14 - N1, B-4000 Liège, Belgium. Phone: (+32) 42327428. E-mail: g.hubner@ulg.ac.be

${ }^{\S}$ The KBL Chair in Fund Industry, HEC Management School - University of Liège, Belgium. E-mail: Danielle.Sougne@ulg.ac.be.
} 


\section{Introduction}

The assessment of the market timing performance of hedge funds appears to be a useful but difficult task. Because hedge fund managers enjoy much freedom in modifying their asset allocation and leverage, it is natural to anticipate their propensity to time the market, provided that they display genuine anticipation skills. Being able to measure such skills would uncover a significant component of performance. On the other hand, several hindrances make the measurement of such skills challenging. First, the lack of liquidity of many hedge fund strategies (especially the private equity-like ones) prevents not only the investor, but also the fund manager herself to take advantage of potential market opportunities. Further, the high percentage of graveyard funds in hedge fund data samples leads to difficulties in exploiting the time series of returns to extract indicators of market timing skills. But to date, the most important limitations to the measurement of market timing performance at the level of hedge fund managers are probably the difficulty to identify their benchmark portfolios and their low frequency of returns.

The absence of a benchmark makes the use of classical specifications for market timing, such as the Henriksson and Merton (1981) or Treynor and Mazuy (1966) models, hardly applicable. How can a manager time a market index if one does not know what index to time? Indeed, a large body of the hedge fund literature has associated nonlinearities of the return generating process (whether convex or concave patterns) to their exposure to option-based risk premia (see Agarwal and Naik, 2004; Fung and Hsieh, 2004 for the most popular models). This choice, leading the asset pricing model to mimic a structured fund rather than a linear portfolio, not only naturally induces estimation problems from an econometric point of view, but also materializes the incapacity to find out the accurate benchmark portfolio of base financial assets for most of these funds.

The second difficulty associated with timing models for hedge funds lies in the fact that a vast majority of hedge funds report monthly returns. Not only these returns usually feature a smoothing pattern that reflects their lack of liquidity (see Cavenaile, Coën and Hübner, 2011), but such frequency makes it also arduous to emphasize a true market timing behavior, as underlined by Bollen and Busse (2001).

In this paper, we revisit the Treynor and Mazuy model (henceforth TM) by applying, almost literally, the original option replication approach proposed by Merton in the context of the HM model, and adapted by Hübner (2010). Doing so, we directly address the issue of hedge fund benchmarking by allowing a hedge fund manager who wishes to adopt a quadratic exposure to an index without any directional beta, as this would typically be the case for an equity market neutral fund for instance, to trade a straddle on this index. The use of a simple multi-factor extension of the TM model provides at least three advantages with respect to the option-based approach. First, 
it is more flexible in the types of exposures that a fund can take on an index. With two variables, the model accommodates the long only, short only, long and convex, long and concave, short and convex, short and concave, convex only, and concave only strategies. Second, it immediately provides the indication of the manager's attempt to time the market, as in the original intent of the TM model. Third and most important, the relation between the portfolio returns and the index provides a precise adjustment of the fund's alpha for convexity based on an arbitrage relation, therefore providing an exact performance measure reflecting the cost of market timing.

We apply our new approach on a sample of hedge funds whose managers are likely to exhibit market timing skills. To maximize the likelihood of detecting market timing if it exists, we frame our database along with three dimensions. In order to better identify potential market timing behaviors of hedge fund managers, we deliberately stick to funds that post weekly returns, and thus that promise a high degree of liquidity to their investors. Second, we analyze two hedge funds strategies in particular: long-short equity funds, and funds of hedge funds. Finally, we analyze a particular period during which the managers of these funds are likely to magnify their presumed skills, namely around the financial and banking crisis of 2008 .

The application of the new correction delivers particularly encouraging empirical results. From our sample, we get that many funds adopt a positive convexity as a response to the US market index, while many others (or sometimes the same) have a concave response to the returns of an emerging market index. Thus, we identify "positive", "mixed" and "negative" market timers. Digging into the determinants of their performance adjusted for convexity, we manage to get a number of signs that positive market timers only manage to acquire options below their cost, and deliver economic significant performance. This even holds in the midst of the financial crisis, and is consistent for funds of hedge funds. Negative market timers, by contrast, behave as if they are compensating their poor results through the premium obtained from selling options, which can be explained by fire sales induces by redemption requests from their investors. As their payoff structure involves short puts on the index, this is a potentially dramatic strategy during market crisis, as shown by our results.

The paper is organized as follows. The second section summarizes the existing literature concerning the market timing skills of hedge funds managers. The third section introduces the adjustment approach, based on an option replicating approach, to account for market timing in performance evaluation. In section 4, we discuss the data and models used in the empirical study, and discuss the results. Section 5 concludes. 


\section{Evidence on market timing of hedge funds}

Thus far, only a few studies relevant to the market timing skills of hedge funds have been carried out. As we can see in Table 1, the results are mixed on the ability of hedge fund managers to time the market. It should be noted that different market timing measures are used by the authors.

Insert Table 1 here

Fung et al. (2002), French and Ko (2007), and Park (2010) provide no evidence of market timing ability on the part of hedge funds. Fung et al. (2002) examine the performance of 115 global equitybased hedge funds with reference to their target geographical markets in the year period 1994-2000. They find that global hedge funds managers do not show positive market timing ability but do demonstrate superior security-selection ability. French and Ko (2007) investigate the determinants of hedge fund portfolio performance - whether hedge funds exhibit security selection skill and market timing skill. They examine a sample of 157 long-short equity hedge funds over the 10-year period from January 1996 through December 2005. To account for nonlinearities, they employ the Treynor and Mazuy (1966) quadratic model. After adjusting their betas for illiquidity, they detect no statistically significant evidence of market timing ability. To examine whether factor timing is a source of hedge fund alpha, Park (2010) decomposes excess return generated by hedge funds during 1994-2008 into security selection, factor timing, and risk premium using the new measure of performance developed by Lo (2008). He finds that most of the excess return generated by hedge funds during 1994-2008 is attributable to security selection and that hedge funds on average could not time the market during this period.

In contrast, Chen and Liang (2007) find economically and statistically significant evidence of timing ability, including return timing, volatility timing, and joint timing, both at the aggregate level and at the individual-fund level. Using a sample from January 1994 to June 2005 of 221 market timing funds, they examine whether self-described market timing hedge funds have the ability to time the U.S. equity market. In addition, they demonstrate that timing ability appears especially strong in bear and volatile markets states. Moreover, they find that small funds and offshore funds tend to time better, other things being equal.

Chen (2005) examines the ability of hedge funds in various investment categories to time their focus markets. Using a sample of 1471 hedge funds from the TASS database during January 1994 through June 2002, the author demonstrates that a few hedge funds categories show ability to time their focus markets, including convertible arbitrage funds in the high yield bond market, global macro funds and managed futures funds in the Non-US bond market and the currency market, and market timing funds in the U.S. equity market at both the category and fund levels. Meanwhile, 
some styles such as event driven show negative timing (concavity) in their focus market.

Monarcha (2010) proposes a new test of market timing, based on the randomization of the dynamic risk structures of hedge funds. He shows that, on average, Managed Futures and Global Macro managers deliver positive market timing, whereas Event Driven and negative value strategies exhibit significant and negative market timing. He attributes this result to liquidity risk exposure and leverage. Strategies that deliver positive alpha also exhibit negative market timing. At the opposite, investment styles that deliver low alpha also deliver positive market timing. Within the same investment style, good market timers deliver lower alpha.

The joint examination of hedge fund managers' market timing abilities during the financial crisis of 2007-08 with weekly data, which is the scope of this paper, are two novelties with respect to this stream of literature.

\section{$3 \quad$ Performance adjustment for market timing}

\subsection{Correcting the Treynor and Mazuy model}

The original Treynor and Mazuy (1966, hereafter TM) model writes:

$$
r_{t}=\alpha_{\mathrm{TM}}+\beta_{\mathrm{TM}} r_{m t}+\gamma_{\mathrm{TM}} r_{m t}^{2}+\varepsilon_{t}
$$

where $r_{t} \equiv R_{t}-R_{f}$ is the portfolio excess return over the risk-free rate, $r_{m t}$ is the market portfolio excess return, $\alpha_{\mathrm{TM}}$ is timing-adjusted alpha and $\gamma_{\mathrm{TM}}$ measures timing ability. A positive exposure to this term indicates the convex nature of the portfolio returns in comparison with market returns. A negative value of $\gamma_{\mathrm{TM}}$ indicates negative market timing.

This model represents a quadratic extension of the Capital Asset Pricing Model with a dynamic beta (see Jensen, 1972) :

$$
r_{t}=\alpha+\beta_{t-1} r_{m t}+\varepsilon_{t}
$$

where

$$
\beta_{t-1}=\beta_{0}+\gamma_{\mathrm{TM}}\left(r_{m t}+n_{t}\right)
$$

Equation (3) reflects the essence of market timing: the fund's market exposure adjusts to the timing signal $\left(r_{m t}+n_{t}\right)$. Admati et al. (1986) show that, under the normality assumption, $\beta_{t-1}$ responds linearly to the timing signal. $\beta_{0}$ is a constant market risk level. Substituting equation (3) into (2) and including the independent zero-mean noise $n$ into error term, we obtain the TM model.

The TM specification can also be seen as a special case of multi-moment asset pricing models, which build on investors' preferences for higher moments than the variance. Kraus and Litzenberger (1976) extended the Capital Asset Pricing Model developed by Treynor (1961), Sharpe (1964) and 
Lintner (1965) in order to incorporate the effect of skewness on valuation. The analytical expression of their three-moment valuation model is identical to the TM specification. Research has also been realized on a four-moment CAPM which takes into account the investor preferences for kurtosis (see for example Jurczenko and Maillet, 2006).

Following the pioneering work of Treynor and Mazuy (1966), many academic studies ${ }^{1}$ have focused on the timing ability of professional portfolio managers. As a preliminary step to achieve this objective, it is necessary to reach a single indicator of performance that accounts for market timing. While several ways to adjust the alpha in equation (1) have been proposed ${ }^{2}$, in this paper, we apply the original approach proposed by Hübner (2010) who associates the market timing return to an option. His analysis focuses on the cost, expressed in returns, of replicating the pattern of the TM regression using a mix of options and risk-free instruments only.

The absence of any market timing skill induces that the levels of beta and gamma coefficients in (1) affect the intercept of the alpha of the regression. Hübner (2010) shows that a simple selffinancing investment strategy that consists in creating a long or short position in an index option and lending or borrowing at the risk-free rate would yield the same levels of directional (beta) and convexity (gamma) exposures. As there exists a range of options whose time-to-maturity and moneyness match the desired sensitivities to the underlying index, the opportunity cost of replicating the cheapest of these options represents the performance level that a passive manager would obtain. In order to reflect the true market timing manager's performance, her observed alpha must be corrected by adding this cost.

Formally, rewrite equation (1) of the actively managed portfolio to replicate in terms of total returns:

$$
R_{t} \simeq \alpha_{\mathrm{TM}}^{\prime}+\beta_{\mathrm{TM}} R_{m t}+\gamma_{\mathrm{TM}} R_{m t}^{2}+\varepsilon_{t}
$$

where $\alpha_{\mathrm{TM}}^{\prime}=\alpha_{\mathrm{TM}}+\left(1-\beta_{\mathrm{TM}}\right) R_{f}$ and the approximate equality comes from $R_{f}^{2} \simeq 0$ and $R_{m t} R_{f} \simeq 0$.

Consider, without loss of generality, that $\beta_{\mathrm{TM}}>0$ and $\gamma_{\mathrm{TM}}>0$. We create a passive portfolio consisting in a long position $w>0$ in a call option on the index, normalized to one. The remainder of the portfolio $(1-w)$ is invested in the risk-free asset. Using the second order Taylor series expansion, the rate of return during the interval $\Delta t$ of the portfolio can be expressed using the "greeks", i.e.

\footnotetext{
${ }^{1}$ A partial list includes Jensen (1972), Merton (1981), Henriksson and Merton (1981), Henriksson (1984), Chang and Lewellen (1984), Admati et al. (1986), Jagannathan and Korajczyk (1986), Grinblatt and Titman (1994), Ferson and Schadt (1996), Becker (1999), Agarwal and Naik (2000, 2004), Goetzmann et al. (2000), Bollen and Busse (2001), Fung and Hsieh (2001), Lo (2008), Comer (2006), Comer et al. (2009), and Monarcha (2011).

${ }^{2}$ Historically, three types of adjustments have been used: a variance correction term (Grinblatt and Titman, 1994); an approximation based on the squared benchmark returns (Bollen and Busse, 2004); and a synthetic option pricing approach on the sqaured market returns (Ingersoll et al., 2007). See Hübner (2010) for a review.
} 
the partial derivatives of the call with respect to selected variables:

$$
R_{t}^{(\tau, \kappa)}=w\left(\Delta_{\tau, \kappa} R_{m t}+\frac{1}{2} \Gamma_{\tau, \kappa} R_{m t}^{2}+\Theta_{\tau, \kappa}\right)+(1-w) R_{f}+o(\Delta t)
$$

where $\tau$ and $\kappa$ are the time-to-maturity and the strike price (expressed as a multiple of the spot price) of the option. The $\Delta_{\tau, \kappa} \equiv \frac{\partial C(M, \tau, \kappa)}{\partial M}, \Gamma_{\tau, \kappa} \equiv \frac{\partial^{2} C(M, \tau, \kappa)}{\partial M^{2}}$ and $\Theta_{\tau, \kappa} \equiv \frac{\partial C(M, \tau, \kappa)}{\partial t}$ are the option delta, gamma and theta. The remaining term $o(\Delta t)$ results from the higher orders of the Taylor series expansion and from the potential rho and vega effects.

Besides the residual term, equations (4) and (5) look very similar. One has to find an option strategy that matches the linear and quadratic sensitivities of (5) with the ones of (4) at the lowest cost. Hübner (2010) shows that the solution is given by selecting an option on the benchmark whose pair $\left(\tau^{*}, \kappa^{*}\right)$ respect the following conditions: ${ }^{3}$

$$
\begin{aligned}
\alpha^{\left(\tau^{*}, \kappa^{*}\right)} & =\max _{\tau, \kappa}\left(w_{\tau, \kappa} \Theta_{\tau, \kappa}+\left(1-w_{\tau, \kappa}\right) R_{f}\right) \\
\text { s.t. } \frac{2 \Delta_{\tau^{*}, \kappa^{*}}}{\Gamma_{\tau^{*}, \kappa^{*}}} & =\frac{\beta_{\mathrm{TM}}}{\gamma_{\mathrm{TM}}} \\
w_{\tau^{*}, \kappa^{*}} & =\frac{\beta_{\mathrm{TM}}}{\Delta_{\tau^{*}, \kappa^{*}}}>\beta_{\mathrm{TM}}
\end{aligned}
$$

The first line reproduces the replication payoff (in terms of returns) of this portfolio, which is maximized by selecting the best option respecting the constraints on the slope and curvature of the portfolio return generating process. Equation (8) ensures that the slope of equation (5) equates that of (4), while (7) allows to match the quadratic coefficients as well.

Finally, the outperformance of the active portfolio that yields the returns (4) over the replicating portfolio is obtained by subtracting the value of $\alpha^{\left(\tau^{*}, \kappa^{*}\right)}$ :

$$
\pi_{\mathrm{TM}}^{*}=\alpha_{\mathrm{TM}}^{\prime}-\alpha^{\left(\tau^{*}, \kappa^{*}\right)}=\alpha_{\mathrm{TM}}+\left(w_{\tau^{*}, \kappa^{*}}-\beta_{\mathrm{TM}}\right) R_{f}-w_{\tau^{*}, \kappa^{*}} \Theta_{\tau^{*}, \kappa^{*}}
$$

As $w_{\tau^{*}, \kappa^{*}}>\beta_{\mathrm{TM}}$ and $\Theta_{\tau^{*}, \kappa^{*}}<0$ (Merton, 1981), both terms of the adjustment are positive for a positive market timer $\left(\gamma_{\mathrm{TM}}>0\right)$. The first one reflects the incremental risk-free return resigned by the passive portfolio through investing a proportion in options higher than the original exposure to the market index. The second term, as in Merton (1981), stands for the time value of the option lost because of the passage of time. In order to generate a neutral performance $\pi_{\mathrm{TM}}^{*}=0$, the regression intercept $\alpha_{\mathrm{TM}}$ is negative.

\footnotetext{
${ }^{3}$ The option chosen should also provide a satisfactory pattern of quadratic returns; otherwise, it is likely that the options with the shortest time-to-maturity $(\tau=\Delta t)$ would be chosen. As this case would collapse to the Henriksson and Merton equation, such a solution should be discarded. In practice, the choice of option maturity must trade off the cost of replicating the option (typically increasing with maturity) with the quality of the quadratic fit (decreasing as maturity decreases). See Hübner (2010) for a discussion.
} 
The mirror case of a negative convexity involves $\gamma_{-\mathrm{TM}}<0$ (where the index - TM means negative market timer) bears a similar analysis. The replicating portfolio involves going short an amount of $-w$ puts on the index and investing $1+w$ in the riskless asset. The performance of the "contrarian" market timer, denoted $\pi_{-\mathrm{TM}}^{*}$, is obtained by the following equation:

$$
\pi_{-\mathrm{TM}}^{*}=\alpha_{-\mathrm{TM}}-\left(w_{\tau^{*}, \kappa^{*}}+\beta_{-\mathrm{TM}}\right) R_{f}+w_{\tau^{*}, \kappa^{*}} \Theta_{\tau^{*}, \kappa^{*}}
$$

where, this time, the second and third term are both negative. In order to post a zero aggregate performance, the manager must deliver a positive alpha from the TM regression.

A manager who chooses to adopt a short position in the underlying risk factor can also be portrayed with this approach. If the beta is negative and the gamma is positive, the corresponding replicating strategy involves going long a put option. If values of both the beta and the gamma are negative, the passive strategy that yields the same exposures is a short call option. The corresponding equations write:

$$
\begin{aligned}
\pi_{\mathrm{TM}}^{\circ} & =\alpha_{\mathrm{TM}}^{\circ}+\left(w_{\tau^{*}, \kappa^{*}}-\beta_{\mathrm{TM}}^{\circ}\right) R_{f}-w_{\tau^{*}, \kappa^{*}} \Theta_{\tau^{*}, \kappa^{*}} \\
\pi_{-\mathrm{TM}}^{\circ} & =\alpha_{-\mathrm{TM}}^{\circ}-\left(w_{\tau^{*}, \kappa^{*}}+\beta_{-\mathrm{TM}}^{\circ}\right) R_{f}+w_{\tau^{*}, \kappa^{*}} \Theta_{\tau^{*}, \kappa^{*}}
\end{aligned}
$$

where superscript ${ }^{\circ}$ indicates a negative beta. As for equations (9) and (10), the sign of the alpha of a passive portfolio is entirely driven by the sign of the gamma: if it is negative, the replicating strategy involves going short an option, and the alpha represents the return obtained from the premium of the sale of the option contract.

Finally, one has to identify the case of a very low beta but a large gamma. The manager of such a fund does not take a directional view on the underlying index, but adopts a strong (positive or negative) convexity. The corresponding passive strategy involving options is a long or short straddle, making the manager (almost) delta neutral but leaving her gamma long or short. The solution of the problem is to split the beta in two parts (a long and a short one) and to make sure that the convexity of each option is identical, given that we do not have further information on the importance of the call versus the put option in the straddle. In the case where $\gamma_{\mathrm{TM}}>0$, considering that $\beta_{\mathrm{TM}}=\beta_{\mathrm{TM}}^{+}+\beta_{\mathrm{TM}}^{-}$where $\beta_{\mathrm{TM}}^{+}>0$ and $\beta_{\mathrm{TM}}^{-}<0$, we set $\gamma_{\mathrm{TM}}=\gamma_{\mathrm{TM}}^{+}+\gamma_{\mathrm{TM}}^{-}$ where $\frac{\beta_{T M}^{+}}{\gamma_{T M}^{+}}=-\frac{\beta_{T M}^{-}}{\gamma_{T M}^{-}}$. Using the same superscripts for the greeks of the call option $(+)$and of the put option $(-)$, the performance of this non-directional fund will be obtained by:

$$
\pi_{\mathrm{TM}}^{n d}=\alpha_{\mathrm{TM}}+\left(w_{\tau^{*}, \kappa^{*}}^{+}+w_{\tau^{*}, \kappa^{*}}^{-}-\beta_{\mathrm{TM}}\right) R_{f}-w_{\tau^{*}, \kappa^{*}}^{+} \Theta_{\tau^{*}, \kappa^{*}}^{+}-w_{\tau^{*}, \kappa^{*}}^{-} \Theta_{\tau^{*}, \kappa^{*}}^{-}
$$

\subsection{The multi-factor extension of the portfolio replicating approach}

The quality of the portfolio replicating approach is sensitive to the model specification, because the quality of the adjustment decreases as specific risk $\sigma\left(\varepsilon_{t}\right)$ increases. Hübner (2010) demonstrates 
that the portfolio replicating approach can be extended to a multi-factor specification. Similarly to Comer (2006), he considers that the linear return generating specification features $K$ risk factors, but only a subset $L \leq K$ are prone to a market timing behavior. For each of these $L$ factors, the linear and quadratic sensitivities can be isolated and the replication process described in the previous section can be reproduced individually for each factor. Formally, we have:

$$
R_{t} \simeq \alpha+\left(1-\sum_{i=1}^{K} \beta_{i}\right) R_{f}+\sum_{i=1}^{K} \beta_{i} R_{i t}+\sum_{i=1}^{L} \gamma_{i} R_{i t}^{2}+\varepsilon_{t}
$$

and the market timing adjusted performance is obtained as follows:

$$
\pi^{*}=\alpha+\left(1-\sum_{i=1}^{K} \beta_{i}\right) R_{f}-\sum_{i=1}^{L} \alpha^{\left(\tau_{i}^{*}, \kappa_{i}^{*}\right)}
$$

where

$$
\alpha^{\left(\tau_{i}^{*}, \kappa_{i}^{*}\right)}=w_{\tau_{i}^{*}, \kappa_{i}^{*}} \Theta_{\tau_{i}^{*}, \kappa_{i}^{*}}+\left(1-w_{\tau_{i}^{*}, \kappa_{i}^{*}}\right) R_{f}
$$

if the beta associated to the $i^{\text {th }}$ factor is statistically significant.

In the case of a very low beta but a large gamma, we apply:

$$
\alpha^{\left(\tau_{i}^{*}, \kappa_{i}^{*}\right)}=w_{\tau_{i}^{*}, \kappa_{i}^{*}}^{+} \Theta_{\tau_{i}^{*}, \kappa_{i}^{*}}^{+}+w_{\tau^{*}, \kappa^{*}}^{-} \Theta_{\tau_{i}^{*}, \kappa_{i}^{*}}^{-}+\left(1-w_{\tau_{i}^{*}, \kappa_{i}^{*}}^{+}-w_{\tau_{i}^{*}, \kappa_{i}^{*}}^{-}\right) R_{f}
$$

\section{The market timing of hedge funds during the crisis}

\subsection{Data and models}

We justify the choice of dependent and independent variables to carry out our analysis of market timing of hedge funds in the special context of the financial crisis.

\subsubsection{Sample selection}

We carry out an empirical analysis with a focus on hedge funds that can be suspected of exhibiting a market timing behavior. To this end, we restrict our sample selection along with three criteria. Firstly, we only analyze hedge funds that post weekly returns. Indeed, hedge funds that adopt a monthly reporting do not warrant sufficient market liquidity to activate genuine market timing. The work by Cavenaile, Coën and Hübner (2011) on monthly data shows that even indices are likely to be heavily contaminated by stale prices; this phenomenon is even more likely to affect individual funds. Given that we aim at identifying, analyzing and evaluating the impact of market timing, we must absolutely rule out any suspicion of lack of underlying asset liquidity for the managers under study. 
As a second constraint, we only study funds belonging to strategies for which a market timing behavior of managers makes full sense, and could be considered as a natural source of abnormal performance. We focus on three strategies: the long/short equity hedge funds (LSHF), the managed futures hedge funds (MFHF), and the multi-strategy funds of hedge funds (FoHF). The first strategy enables the managers to vary their leverage according to their anticipations of market movements, while their target market makes the analysis of risk-adjusted returns relatively easy to handle. The second strategy is based on trading activities, whether discretionary or systematic; most of the managed futures funds are trend-following, which involves that their performance is driven by their market timing skills. The third strategy, combined with the weekly frequency of returns, addresses the tactical allocation skill of managers who can select multiple managers and multiple strategies.

Our last constraint is related to the period under study. The equity market had experienced two long and pronounced directional trends since the explosion of the dot-net bubble in 2000: a bearish period until March 2003, then a bullish period that ended up in the second half of 2007, with the blowout of two hedge funds owned by Bear Stearns and that was the first trigger of the banking and financial crisis that erupted in 2008. The shaky, particularly volatile period July 2007 - December 2008 is presumably an excellent laboratory for a market timer who would not be bound by too strong volatility constraints. A good, persistent market timer who would show these types of skills during a "normal" period should be able to confirm them during this very turbulent market period. For this reason, we collect data for three years (156 weeks), from 6 January 2006 to 26 December 2008. The first half of the sample period, which end on 15 June 2007, serves as a proof-of-skill period, while the second half represents the acid test of proof-of-persistence. Note that the selection criterion is only that the funds must be active between 2006 and 2008 .

Altogether, the application of these three constraints prevents us from simply relying on major hedge fund data sources, that publish monthly returns. This leaves us with a sample of $98 \mathrm{long} / \mathrm{short}$ equity hedge funds, 43 managed futures hedge funds, and 118 multi-strategy funds of hedge funds with data available on Bloomberg. The sample features 54 active LSHFs, 44 dead LSHFs, 37 active MFHFs, 6 dead MFHFs, 73 active FoHFs and 45 dead FoHFs.

\subsubsection{Asset pricing specifications}

We specify a multi-factor Treynor-Mazuy model to the individual sample observations. For this purpose, it is necessary to adopt a specification that would not contaminate the quadratic term of the model as in (14) with option-related risk factors. This forces us to rule out the nowadays classical sets of factors proposed by Aggarwal and Naik (2004) and Fung and Hsieh (2001, 2004), which both involve returns of option-based strategies. Nevertheless, the linear directional risk premia proposed by these authors are eligible in our setup. On this basis, we build a basic zero-cost 5 -factor asset 
pricing model based on investable indexes, borrowed from the linear factors of Fung and Hsieh (2004), that is likely to apply to all individual funds for both sub-periods as well as for the entire period. The risk premia reflect equity risk, the small caps premium, the term premium, the credit premium, and the emerging market equity returns. Thus, the linear asset pricing specification has the following form:

$$
\begin{aligned}
R_{t}-R_{f}= & \alpha_{5 F}+\beta_{1}\left(R_{S P 500, t}-R_{f}\right)+\beta_{2}\left(R_{R u s s 2000, t}-R_{S P 500, t}\right)+\beta_{3} L G B_{t}+\beta_{4}\left(H Y_{t}-L G B_{t}\right) \\
& +\beta_{5}\left(R_{E M, t}-R_{f}\right)+\varepsilon_{t}
\end{aligned}
$$

where $R_{t}$ is the return of the fund for period $t, R_{f}$ is the average 1-month U.S. Treasury Bills rate for the period of study, $R_{S P 500, t}, R_{R u s s 2000, t}, L G B_{t}, H Y_{t}, R_{E M, t}$ are respectively, the returns of the Standard\&Poor's 500 index, the Russell 2000 index, the Barclays U.S. Treasury 7-10 years index, the Bank of America Merrill Lynch U.S. High Yield Master II index, and the MSCI emerging markets index.

From a preliminary analysis of the types of skills activated by the managers of these funds, it appears that they mostly tend to time two markets: the domestic (US) market and the emerging market. There is hardly any significant quadratic term to be retrieved from the other three risk premia. Therefore, the multi-factor Treynor-Mazuy specification applied to our sample is:

$$
\begin{aligned}
R_{t}-R_{f}= & \alpha_{5 F-\mathrm{TM}}+\beta_{1}\left(R_{S P 500, t}-R_{f}\right)+\beta_{2}\left(R_{R u s s 2000, t}-R_{S P 500, t}\right)+\beta_{3} L G B_{t}+\beta_{4}\left(H Y_{t}-L G B_{t}\right) \\
& +\beta_{5}\left(R_{E M, t}-R_{f}\right)+\gamma_{1}\left(R_{S P 500, t}-R_{f}\right)^{2}+\gamma_{2}\left(R_{E M, t}-R_{f}\right)^{2}+\varepsilon_{t}
\end{aligned}
$$

The models are estimated for the whole period (6 January 2006 - 26 December 2008), the precrisis period (6 January 2006 - 15 June 2007) and the crisis period (22 June 2007- 26 December 2008). Table 2 reports the descriptive statistics for the set of dependent variables as well as for the five linear and two quadratic variables.

\section{Insert Table 2 here}

Table 2 shows that, as expected, the excess returns for both strategies were on average negative during the three-year time window. This is entirely due to the second (crisis) sub-period. However, given that we study the abnormal returns of these funds, this is not per se disturbing as both equity risk premium and the credit risk premium share a similar behavior. Individual hedge funds posted larger levels (in absolute value) and volatility of returns than FoHF. The proportion is close to two-to-one for both the mean and standard deviation of returns.

Note also that the volatility of the S\&P500 index excess returns is lower than the one of the emerging market index for all three periods. The proportion is approximately $2 / 3$ overall, and also during the crisis period. Such a result indicates that it is considerably more expensive to replicate an option on emerging equity markets than on the US stock markets during all periods. 


\subsection{Results and interpretations}

\subsubsection{Market timing activity}

We estimate equation (18) on all 98 LSHF, 43 MFHF and 118 FoHF for the whole period and both sub-periods. The summary results of the estimation are displayed in Table 3.

Insert Table 3 here

The significance level achieved with the quadratic specification remains around above $30 \%$ for LSHF, and 25\% for MFHF and FoHF. Being averages across single funds for a short and shaky period, this is not a bad achievement. The quadratic terms bring, on average, 3 to $5 \%$ of additional significance over the linear model. The alpha is in general positive before, and negative during the crisis, except for MFHF that post almost no alpha. Overall, very few funds post significant alphas for the whole period. Not surprisingly, given the particular market atmosphere during the period and the need for hedge fund managers to post higher returns than their mutual fund peers, the exposure to the emerging equity market is more pronounced than on the US market. Many FoHF managers appear to arbitrage their negative exposure to the $\mathrm{S} \& \mathrm{P}$ with a positive one the emerging market index. The exposure to small caps shifts from the pre-crisis (in general positive) to the crisis period, where is becomes negative. This might be explained by the surge for liquidity that lead many managers to favor larger caps when the markets became turbulent.

We identify that most of the positive market timing is done on the S\&P500 index $\left(\gamma_{1}\right)$, while the negative quadratic coefficients are primarily observed for the emerging market term $\left(\gamma_{2}\right)$. Stated in terms of option strategies, and combined with the dominant signs for $\beta_{1}$ and $\beta_{5}$, this looks like most managers, especially in the LSHF and FoHF strategies, entered positions that replicate a long put on the US market index (negative delta, positive gamma) and/or a short put on the emerging market index (positive delta, negative gamma). To dig deeper in this direction, we provide the detail of market timing behaviors in Table 4 .

\section{Insert Table 4 here}

This table reports the market timing attitudes of fund managers. The table is organized by behavior of managers. She is a positive market timer if at least one gamma coefficient is significantly positive and none is negative; a mixed market timer is the coefficients are of opposite signs and significant, and a negative market timer is at least one gamma is negative while none is positive.

The results of this table globally confirm the findings of Table 3. Most of the market timing with positive convexity is applied on the US market index, while negative market timing is mainly observed on the emerging markets. Very few funds adopt simultaneous positive or negative exposures 
to both markets. Note that the main difference between the pre-crisis and the crisis periods is the reduction of negative market timing activity for all types of managers. There is no major shift of market timing activity for positive market timers from one period to another.

\subsubsection{Performance correction for market timing}

For practical applications, we adopt an constant option maturity of 4 weeks for all replication strategies. As shown by Hübner (2010), this choice of a short option maturity opens the largest range of

possible values for the ratio $\frac{\beta_{i}}{\gamma_{i}}$ for both indexes, while still providing a good correspondence between the Taylor series expansion of replicating portfolio returns and the TM equation. Furthermore, when the beta of a fund is insignificant, we adopt the procedure explained in equation (13) with a value of $\beta_{i}^{+}$normalized to 1 .

Table 5 reports the performance measures obtained from different specifications. We estimate the Fama-French-Carhart classical four-factor model as well as the linear version of the five-factor model to benchmark our results.

\section{Insert Table 5 here}

The results retrieved from Table 5 deliver a striking picture of the relation between market timing exposures and associated performance.

For LSHF, the performance assessed with linear models is always negative for the whole period as well as for the crisis sub-period. It is positive for the pre-crisis period. Once the quadratic model is applied, the picture changes dramatically. For the global sample time window, the unadjusted performance slightly deteriorates for positive market timers, but substantially improves for mixed and negative market timers. A similar behavior is observed for both sub-periods. But the adjustment for the fund's returns convexity considerably modifies the diagnosis. The adjustment is typically very high, but brings the alpha closer to the ones of the linear model. For positive market timers, the alpha heads the positive values even during the crisis. For mixed market timers, the correction leads to a downward correction of the alpha. This is mainly due to the fact that the option shorted, which is usually the one on the emerging market index, is more expensive than the one on the US market index, which is typically longed by the mixed managers. Negative market timers post overall negative adjusted performance, even during the pre-crisis period.

Managers belonging to the MFHF strategy who actively time the market report consistently positive performance during all periods. Conversely, negative market timers get very negative performance. Even though the number of cases is not sufficient to derive meaningful statistical inference, it is interesting to note that the picture delivered by the TM model provides much clearer impressions than the linear asset pricing models. 
For FoHF, the phenomenon is largely similar, but the results brought by the market timing correction are even more consistent across periods. While linear models lead to a clear distinction between the two sub-periods, with all funds ending up with average positive alphas in the pre-crisis period and negative alphas during the crisis, the adjustment for market timing shows that positive market timers get alphas around $10 \%$ over all three time windows. The poor performance of negative market timers is more pronounced during the crisis.

\subsubsection{Is market timing a skill?}

The interpretation of Table 5 could be that positive market timers, who replicate a long put during the period, usually manage to create this put from dynamic strategies that cost less than the returns they obtain. Even when the market plummets as in 2007-08, the value of the put that they create exceeds its cost, leading to a positive abnormal return. The skills of FoHF and MFHF managers appears more consistent than single long/short equity HF managers. The fact that usually the funds of hedge funds managers replicate a long put option is obviously very valuable in crisis periods, but the fact that the performance is even higher during the pre-crisis period (when markets were still going up) is informative as most of these puts ended out-of-the-money. If they had merely been purchased, the performance of positive market timers would probably have been disappointing.

For negative market timers, we have a radically different overall picture. The adjustment for market timing is very high, especially for LSHF and MFHF. This adjustment represents the return premium obtained from the sale of their puts. Their reported alphas are not high enough, and even stay negative during the crisis. As a consequence, they report extremely negative performances during the 2007-08 period, where their short position in convexity hits them like a boomerang. Evidence in this table seems to indicate that negative market timers are induced to replicate a short put through a damageable trading pattern: the more the market goes down, the more they sell. Such a phenomenon can be explained by fire sales consecutive to massive redemptions by investors. The necessity to get fresh money to meet these redemption notices has presumably induced some managers to liquidate their least solid positions, namely in emerging markets, with losses whose magnitude would be reinforced by the urgency of their trades. This flow-based explanation to a similar extent matches the one given by Warther (1995) in the context of mutual funds. Note that mixed market timers underperform less than negative market timers but their problem is similar during the crisis.

If our interpretation is right, there should be a relationship between the extent of market timing skills and the associated performance. Moreover, this effect should be positive and pronounced for positive market timers, and much less for negative or mixed market timers. In Figures 2 and 3, we plot the adjusted performance of LSHF (Figure 1) and FoHF (Figure 2) as a function of the 
values of $\gamma_{1}$ (for positive market timers) and $\gamma_{2}$ (for negative market timers). We also report the four-factor alpha as a check.

Insert Figures 1 and 2 here

In Figure 1, we mostly emphasize the poor adjusted performance of negative market timing hedge funds, especially during the crisis. The positive relation between adjusted performance and market timing coefficient only obtains in Figure 1b, which reports the results for the pre-crisis period. Note that the adjusted regression line always shows a more negative (or less positive) slope than the one for the four-factor alpha for negative market timers, and always more positive (or less negative) for positive market timers. We can therefore emphasize the inverse relation between market timing on emerging markets and adjusted performance, but there does not appear to be strong validation of a positive relation between convexity and performance for market timers, except on the pre-crisis period. The fire sale hypothesis, leading to a negative convexity of returns and large losses due to massive liquidations in down markets, seems to be the leading explanation for long/short managers.

The impression regarding market timing skills delivered in Figure 2 is much stronger, both for negative and for positive market timers. As expected, the stronger the market timing, the more pronounced the performance. The four-factor alpha reveals unable to magnify this relation, especially for positive market timers during the crisis (Figure 2e).

This all remains visual evidence due to the small number of observations, but the reproduction of these results across graphs makes it quite convincing.

The correlation analysis presented in Table 6 gives an global view of the link between convexity and performance. In order to have a sufficient number of data to build correlations, we aggregate the LSHF, MHFH and FoHF samples by period. For comparison purposes, we only keep positive market timers having a positive and significant $\gamma_{1}$ and a non-significant $\gamma_{2}$. Similarly, we only study negative market timers having a negative and significant $\gamma_{2}$ and a non-significant $\gamma_{1}$.

\section{Insert Table 6}

For positive market timers, we observe strong positive correlations between the fund's performance and convexity during the total period and the two sub-periods. The correlation between $\gamma_{1}$ and the linear alphas is very low in all cases, which confirms that linear specifications are unable to identify market timing behaviors.

We identify many more negative market timers than positive ones, and this reinforces the interest of these results. It looks like market timing is a skill, and this skill can be produced during times of crisis as well. The choice - or more likely the obligation - of adopting a negative convexity would be 
related to disappointing results of the fund's management. The strong positive correlation between $\gamma_{2}$.and the linear alphas, suggesting that the poorer the performance, the more concave the fund's behavior, lends support to the hypothesis of forced adoption of negative convexity. Thus, we can to the limited extent of the scope of this study - validate the notion of "skill" for positive market timers only.

\section{Conclusion}

In this paper, we have studied the skills of three categories of hedge funds regarding their ability to time the market. The adopted specification properly accounts for the non-linearity of the return generating process of market timers. To achieve this objective, we tried to set the best possible conditions to identify these skills, by getting rid, as much as possible, of liquidity issues, benchmark misspecification, or inadequate time periods. The results are to some extent impressive, especially for multi-managers funds of hedge funds. Positive market timers appear to apply some sort of "skill", while negative market timers behave as if they were shorting contracts without getting an adequate premium, especially when the financial crisis blew the hardest. A close look at our results reveals that the poor performance of negative market timers can be explained by the market liquidity issue, leading them to support large losses due to fire sales on emerging markets because of redemption constraints. As the overall fund flows to the hedge fund industry was pervasively negative during the crisis, a mirroring interpretation of positive flows is not likely to provide a satisfactory explanation for the positive performance of the few positive market timers identified in this study.

One may wonder whether this picture could simply result from a bias in the correction of raw performance (alpha) proposed in this paper. Comparing with the linear asset pricing specifications reveals that this is not likely to be the case. Indeed, even though it is less pronounced, the impression left by applying linear models is similar. What these models fail to do, however, is to reveal the consistency of performance over time.

We acknowledge however that much needs to be done in order to ensure that the correction for the cost of replicating the convexity of the market timer deserves special care. Even though the underlying theory, borrowed from Merton (1981), appears to be robust and intuitive, numerical and econometric issues must be solved before the adjustment to the performance of a market timer becomes extremely precise. Our findings suggest, however, that market timing can be found, that it is scarce, and it may even hold during turbulent periods like the 2007-08 financial crisis. 


\section{References}

Admati, A., S. Bhattacharya, P. Pfleiderer, and S. Ross. 1986. On Timing and Selectivity. Journal of Finance 41: 715-32.

Agarwal, V. and Naik, N., 2000. Multi-Period Performance Persistence Analyisis of Hedge Funds. Journal of Financial and Quantitative Analysis 35: 327-342.

Agarwal, V. and Naik, N., 2004. Risks and portfolio decisions involving hedge funds, Review of Financial Studies, 17 (1).

Becker, C., Ferson, W. E., Myers, D. H., and Schill, M. J., 1999. Conditional market timing with benchmark investors. Journal of Financial Economics 52: 119-148.

Bollen, N. P. B., and Busse, J. A. 2001. On the Timing Ability of Mutual Fund Managers. Journal of Finance 56: 1075-1094.

Bollen, N. P. B., and Busse, J. A. 2004. Short-Term Persistence in Mutual Fund Performance. Review of Financial Studies 18: 569-597.

Carhart, M., 1997. On Persistence in Mutual Fund Performance. Journal of Finance 52: 57-82. Cavenaile, L., Coën, A. and Hübner, G. 2011. The Impact of Illiquidity and Higher Moments of Hedge Fund Returns on their Risk-Adjusted Performance and Diversification Potential, Journal of Alternative Investments 13 (4): 9-29.

Chang, E., Lewellen, W., 1984. Market Timing and Mutual Fund Investment performance. Journal of Business 57: 57-72.

Chen Y., 2007. Timing Ability in the Focus Market of Hedge Funds. Journal of Investment Management 5.

Chen Y., Liang B., 2007. Do Market Timing Hedge Funds Time the Market? Journal of Financial and Quantitative Analysis 42 (4).

Comer, G. 2006. Hybrid Mutual Funds and Market Timing Performance. Journal of Business 79:771-97.

Comer, G., Larrymore, N., and Rodriguez, J. 2009. Controlling for fixed income exposure in portfolio evaluation: Evidence from hybrid mutual funds. Review of Financial Studies 22: 481-507.

Fama, E., and K. French, 1993. Common Risk Factors in the Returns on Stocks and Bonds. Journal of Financial Economics 33: 3-56.

Ferson, W., Schadt, R., 1996. Measuring Fund Strategy and Performance in Changing Economic Conditions. Journal of Finance 51: 425-462.

French C., Ko D., 2007. How Hedge Funds Beat the Market? Journal of Investment Management $5(2)$.

Fung, H. G., Xu X.E. and Yau J., 2002. Global Hedge Funds: Risk, Return, and Market Timing. 
Financial Analysts Journal 58: 19-30.

Fung, W., and Hsieh, D. A., 2001. The risk in hedge fund strategies: theory and evidence from trend followers, Review of Financial Studies, 14 (2).

Fung, W., and Hsieh, D. A., 2004. Hedge fund benchmarks: a risk based approach, Financial Analysts Journal, 60: 65-80..

Goetzmann, W., Ingersoll, J., Ivkovich, Z., 2000. Monthly Measurement of Daily Timers. Journal of Financial and Quantitative Analysis 35: 257-290.

Grinblatt, M., and Titman, S. 1994. A study of monthly mutual fund returns and performance evaluation techniques. Journal of Financial and Quantitative Analysis 29: 419-444.

Henriksson, R. D., and R. C. Merton, 1981. On Market Timing and Investment Performance. II. Statistical Procedures for Evaluating Forecasting Skills. Journal of Business 54: 513-33.

Henriksson, R. D., 1984. Market Timing and mutual Fund Performance: An Empirical Investigation. Journal of Business 57: 73-96.

Hübner, G., 2010. The Alpha of a Market Timer. Working Paper, HEC Management School University of Liège.

Ingersoll, J., Spiegel, M., Goetzmann, W., and Welch, I., 2007. Portfolio Performance Manipulation and Manipulation-proof Performance Measures. Review of Financial Studies 20: $1503-1546$.

Jagannathan, R., and R. Korajczyk, 1986. Assessing the Market Timing Performance of Managed Portfolios. Journal of Business 59: 217-35.

Jensen, M., 1972. Optimal Utilization of Market Forecasts and the Evaluation of Investment Performance. Mathematical Methods in Finance, North-Holland.

Jurczenko E. and B. Maillet, 2006. The Four-moment Capital Asset Pricing Model: between Asset Pricing and Asset Allocation. In Multi-moment Asset Allocation and Pricing Models, Jurczenko-Maillet (Eds), John Wiley \& Sons - New-York, Chapter 6, 113-164.

Kraus, A. and Litzenberger, R. H., 1976. Skewness preference and the valuation of risk assets. Journal of Finance 31: 1085-1099.

Lintner, J., 1965. The valuation of risk assets and the selection of risky investments in stock portfolios and capital budgets, Review of Economics and Statistics 47: 13-37.

Lo, A., 2008. Where Do Alphas Come From? A Measure of the Value of Active Investment Management. Journal of Investment Management 6 (2).

Merton, R. C. 1981. On Market Timing and Investment Performance. I. An Equilibrium Theory of Value for Market Forecasts. Journal of Business 54: 363-406.

Monarcha, G., 2011. A dynamic Style Analysis Model for Hedge Funds. Quantitative Research $\mathrm{n}^{\circ} 1$, Orion Financial Partners, Paris. 
Park H., 2010. Can Factor Timing Explain Hedge Fund Alpha? Working Paper, Minnesota State University.

Sharpe, W. F., 1964. Capital asset prices: A theory for market equilibrium under conditions of risk. Journal of Finance 19: 425-442.

Treynor, J. L., 1961. Toward a theory of market value of risky assets. Mimeo, subsequently published in R. A. Korajczyk (ed.) (1999) Asset Pricing and Portfolios Performance: Models, Strategy and Performance Metrics, Risk Books, London.

Treynor, J., and Mazuy, K., 1966. Can Mutual Funds Outguess the Market? Harvard Business Review 44 (July-August):131-136.

Warther, V. A., 1995. Aggregate mutual fund flows and security returns, Journal of Financial Economics 39: 209-235. 


\section{Figures}

Figure 1: Performance of LSHF as a function of market timing coefficients

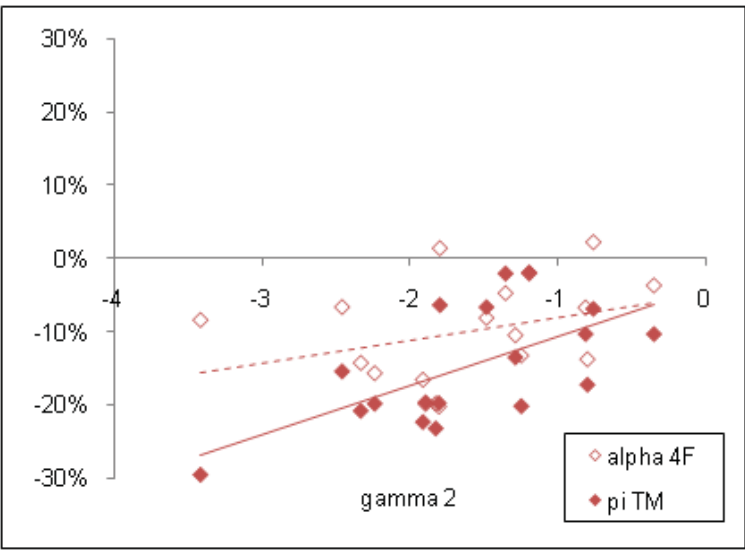

Figure 1a: Negative market timers - 2006-08

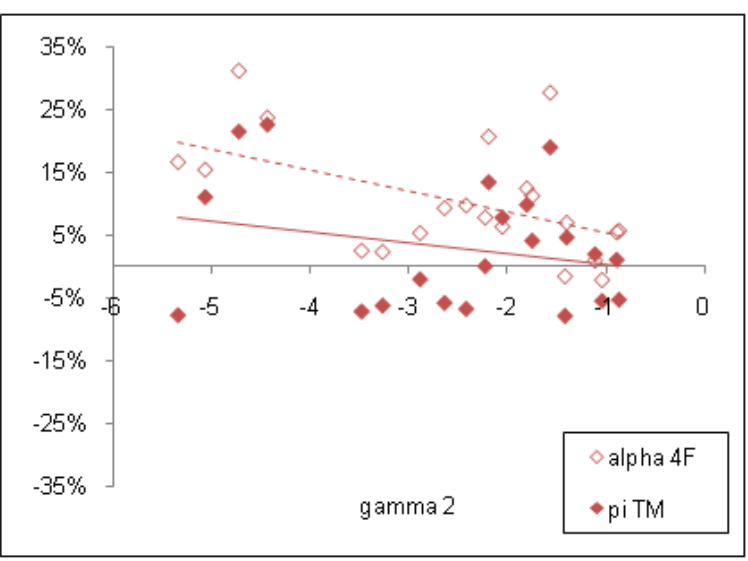

Figure 1c: Negative market timers - 2006-07

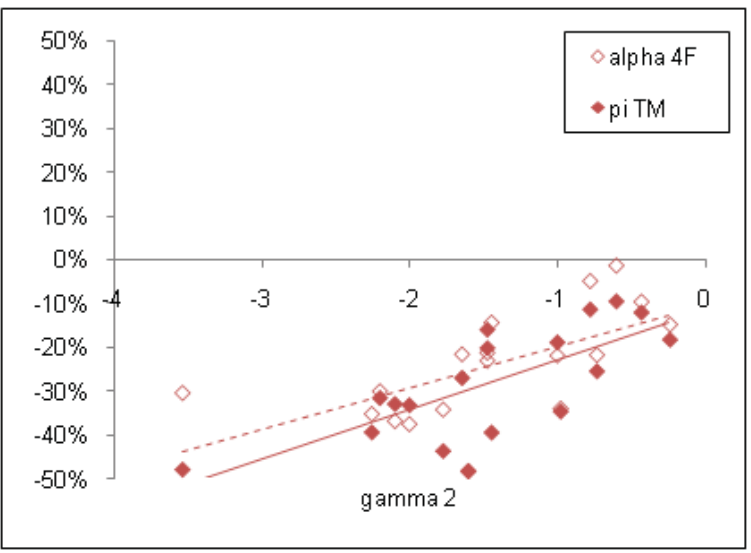

Figure 1e: Negative market timers - 2007-08

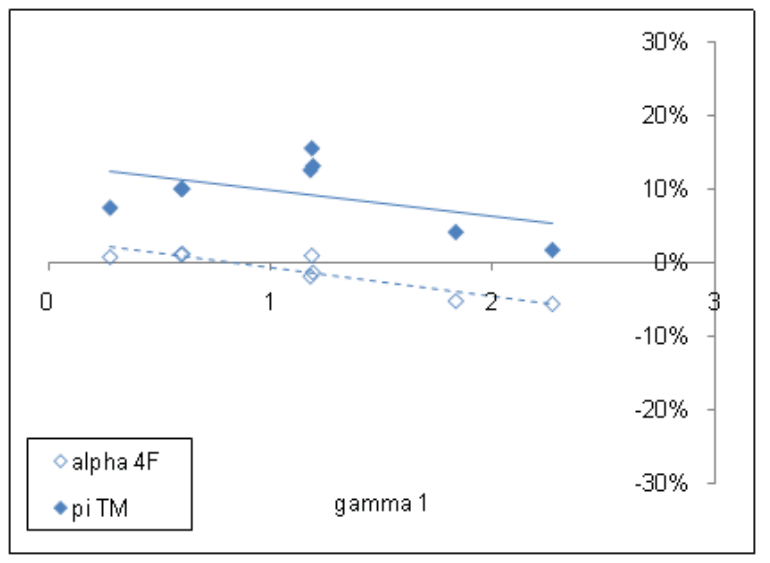

Figure 1b: Positive market timers - 2006-08

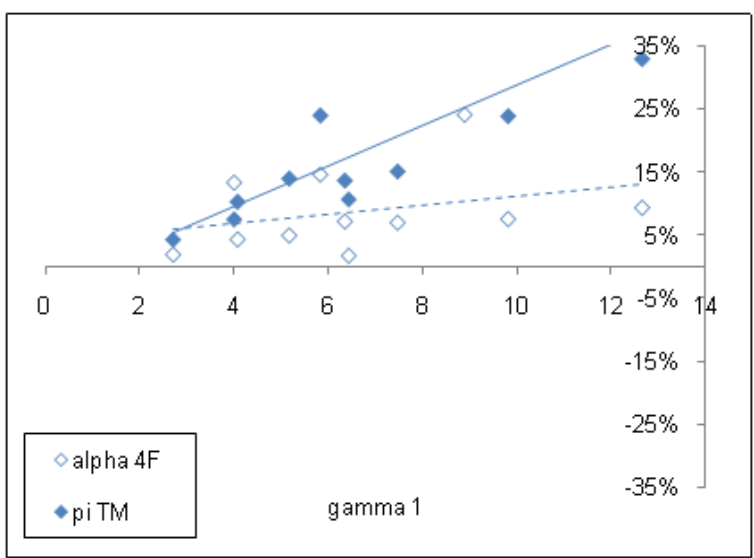

Figure 1d: Positive market timers - 2006-07

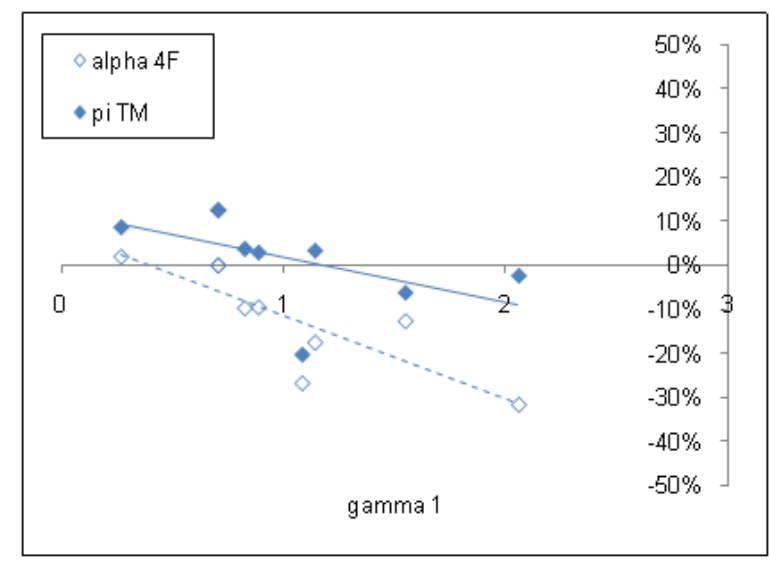

Figure 1f: Positive market timers - 2007-08 
This figure represents the adjusted performance $\pi_{\mathrm{TM}}^{*}$ and four-factor alpha $\left(\alpha_{4 F}\right)$ of long/short hedge funds (LSHF) as a function of their market timing coefficient during the whole period (6 January 2006 - 26 December 2008), the pre-crisis period (6 January 2006 - 15 June 2007) and the crisis period (22 June 2007- 26 December 2008). For negative market timers, we only report the $\pi_{\mathrm{TM}}^{*}$ as a function of $\gamma_{2}$. For posittive market timers, we only report the $\pi_{\mathrm{TM}}^{*}$ as a function of $\gamma_{1}$. 
Figure 2: Performance of FoHF as a function of market timing coefficients

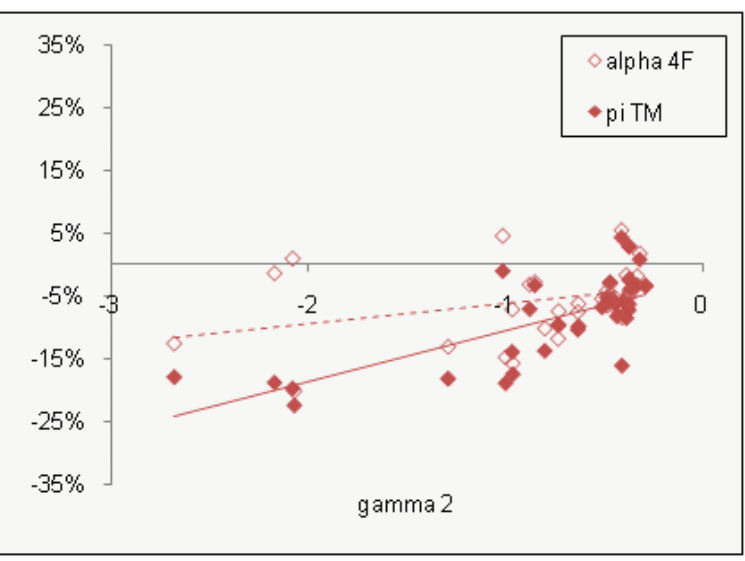

Figure 2a: Negative market timers - 2006-08

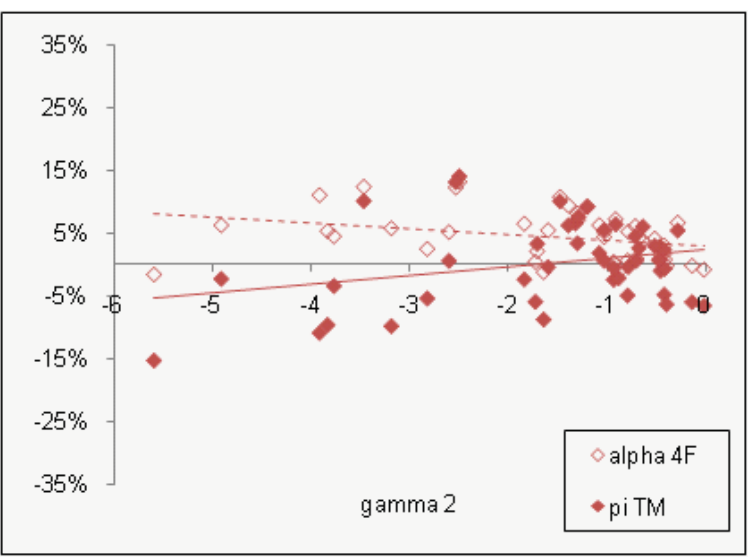

Figure 2c: Negative market timers - 2006-07

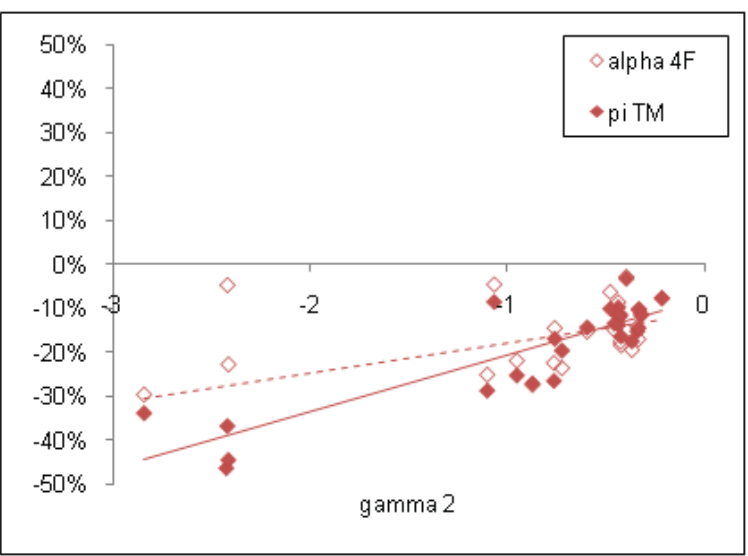

Figure 2e: Negative market timers - 2007-08

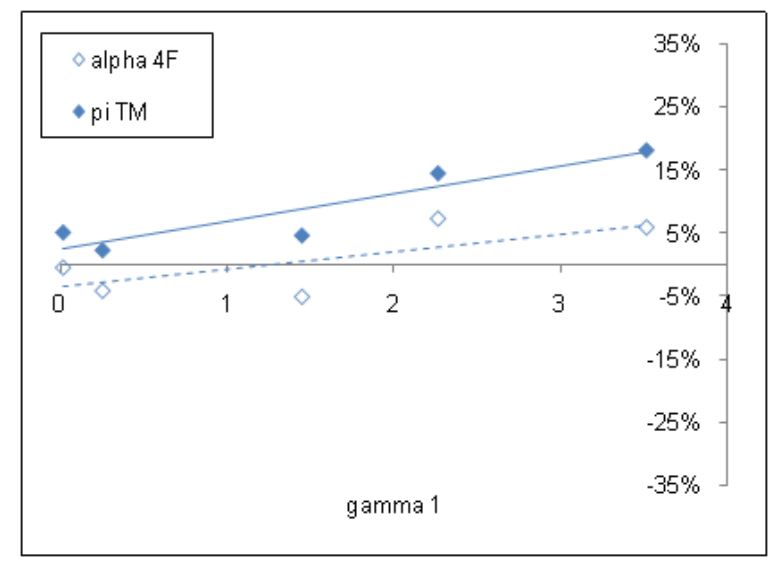

Figure 2b: Positive market timers - 2006-08

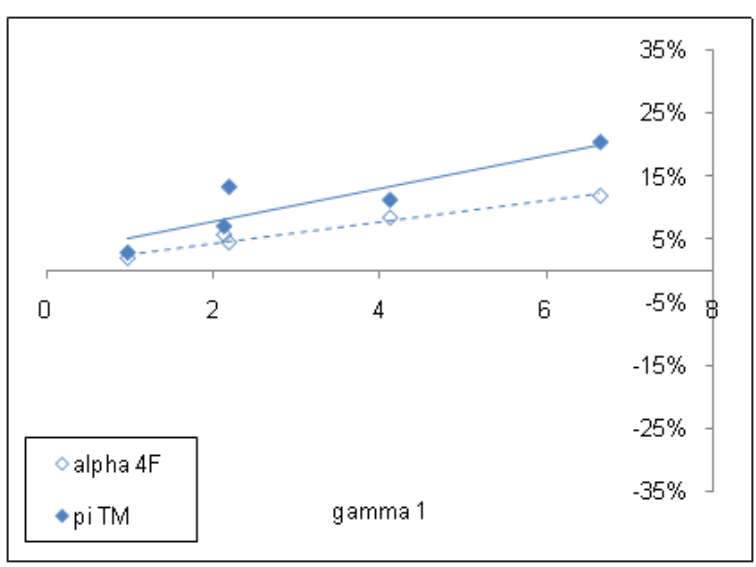

Figure 2d: Positive market timers - 2006-07

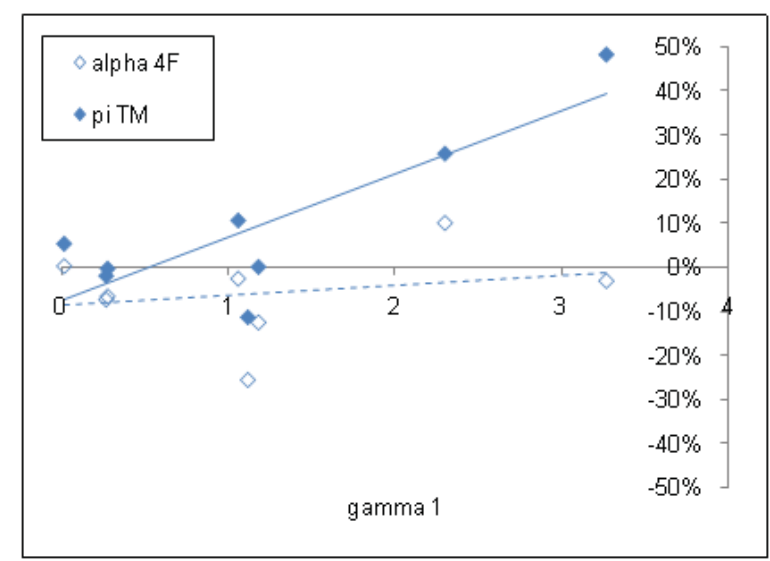

Figure 2f: Positive market timers - 2007-08 
This figure represents the adjusted performance $\pi_{\mathrm{TM}}^{*}$ and four-factor alpha $\left(\alpha_{4 F}\right)$ of funds of hedge funds (FoHF) as a function of their market timing coefficient during the whole period (6 January 2006 - 26 December 2008), the pre-crisis period (6 January 2006 - 15 June 2007) and the crisis period (22 June 2007- 26 December 2008). For negative market timers, we only report the $\pi_{\mathrm{TM}}^{*}$ as a function of $\gamma_{2}$. For posittive market timers, we only report the $\pi_{\mathrm{TM}}^{*}$ as a function of $\gamma_{1}$. 


\section{Tables}

Table 1: Summary of existing literature on the market timing of hedge funds

\begin{tabular}{|c|c|c|c|c|c|}
\hline Authors & Period & Database & Fund universe & Market timing measure & Market timing activity \\
\hline Cheng and Liang & $1994-2005$ & $\begin{array}{l}\text { CISMD, HFR, } \\
\text { TASS }\end{array}$ & $\begin{array}{l}221 \text { market timing } \\
\text { funds }\end{array}$ & $\begin{array}{l}\text { New market timing measure consis- } \\
\text { tent with the models of Jensen (1972) } \\
\text { and Adamati et al. (1986). It jointly } \\
\text { tests for return timing and volatility } \\
\text { timing }\end{array}$ & Yes \\
\hline French and Ko & 1996-2005 & TASS & $\begin{array}{l}157 \mathrm{~L} / \mathrm{S} \text { equity } \\
\text { funds }\end{array}$ & $\begin{array}{l}\text { Market timing measure of the TM } \\
\text { (1966) model }\end{array}$ & No \\
\hline Park & 1994-2008 & TASS & 6114 funds & $\begin{array}{l}\text { Factor timing is measured by the co- } \\
\text { variance between factor loading and } \\
\text { factor risk premium (Lo, 2008) }\end{array}$ & No \\
\hline Monarcha & 2003-2008 & TASS & 6700 funds & $\begin{array}{l}\text { New market timing measure based } \\
\text { on a dynamic style analysis model } \\
\text { (Monarcha, 2008) }\end{array}$ & $\begin{array}{l}\text { "Managed futures" and "global } \\
\text { macro": yes. "Event driven" and } \\
\text { "relative value": no }\end{array}$ \\
\hline Chen & 1994-2002 & TASS & 1471 funds & $\begin{array}{l}\text { Conditional timing ability from the } \\
\text { conditional multi-factor TM (1966) } \\
\text { and Henriksson-Merton (1981) models }\end{array}$ & $\begin{array}{l}\text { "Convertible arbitrage", "global } \\
\text { macro", "managed futures": yes. } \\
\text { "Event driven", "emerging market", } \\
\text { "fixed income arbitrage": negative } \\
\text { market timing }\end{array}$ \\
\hline Fung and $\mathrm{Xu}$ & 1994-2000 & MAR & $\begin{array}{l}115 \text { global equity- } \\
\text { based funds }\end{array}$ & $\begin{array}{l}\text { Market timing measure of the } \\
\text { Henriksson-Merton (1981) model }\end{array}$ & No \\
\hline
\end{tabular}


Table 2: Descriptive statistics of the samples

\begin{tabular}{|c|c|c|c|c|c|c|c|}
\hline & & \multicolumn{6}{|c|}{ Period } \\
\hline & & \multicolumn{2}{|c|}{$2006-2008$} & \multicolumn{2}{|c|}{ 2006-06:2007 } & \multicolumn{2}{|c|}{ 07:2007-2008 } \\
\hline & & mean & s.d. & mean & s.d. & mean & s.d. \\
\hline \multirow[t]{3}{*}{ Dependent variables } & LSHF excess returns & -8.40 & 18.35 & 10.67 & 11.73 & -23.50 & 22.46 \\
\hline & MFHF excess returns & 1.17 & 25.52 & 5.09 & 18.95 & -2.42 & 30.05 \\
\hline & FoHF excess returns & -3.92 & 10.04 & 6.39 & 6.28 & -12.81 & 12.36 \\
\hline \multirow[t]{7}{*}{ Independent variables } & $R_{S P 500, t}-R_{f}$ & -10.33 & 21.62 & 13.94 & 10.27 & -28.65 & 28.13 \\
\hline & $R_{R u s s 2000, t}-R_{S P 500, t}$ & 1.06 & 11.03 & 1.80 & 8.42 & 0.36 & 13.03 \\
\hline & $L G B_{t}$ & 6.29 & 6.65 & -0.82 & 4.57 & 13.50 & 8.05 \\
\hline & $H Y_{t}-L G B_{t}$ & -16.77 & 14.66 & 2.71 & 8.78 & -31.89 & 18.17 \\
\hline & $R_{E M, t}-R_{f}$ & -3.86 & 31.84 & 32.33 & 18.23 & -29.16 & 40.31 \\
\hline & $\left(R_{S P 500, t}-R_{f}\right)^{2}$ & 0.09 & 0.31 & 0.02 & 0.03 & 0.16 & 0.43 \\
\hline & $\left(R_{E M, t}-R_{f}\right)^{2}$ & 0.20 & 0.55 & 0.07 & 0.13 & 0.32 & 0.74 \\
\hline
\end{tabular}

The statistics of all variables are reported in percentage terms. The mean and the volatility of the dependent and the linear independent variables are reported in yearly terms while the statistics of the quadratic terms are not annualized. 
Table 3: Summary results of the estimation

Table 3a: Summary results of the estimation - LSHF

\begin{tabular}{ccccccccccc}
\hline \hline & \multicolumn{1}{c}{ LSHF } \\
\cline { 2 - 11 } Period & $2006-2008$ & \multicolumn{1}{c}{$2006-06: 2007$} & \multicolumn{3}{c}{$07: 2007-2008$} \\
$R_{\text {adj }}^{2}$ & \multicolumn{2}{c}{$32.5 \%$} & \multicolumn{3}{c}{$31.0 \%$} & \multicolumn{3}{c}{$33.9 \%$} \\
& mean & $>0$ & $<0$ & mean & $>0$ & $<0$ & mean & $>0$ & $<0$ \\
\hline$\alpha_{5 F-\mathrm{TM}}$ & -0.32 & 7 & 10 & 8.19 & 30 & 2 & -8.58 & 1 & 21 \\
$\beta_{1}$ & 0.00 & 21 & 24 & -0.02 & 22 & 17 & 0.02 & 23 & 21 \\
$\beta_{2}$ & -0.04 & 3 & 14 & 0.13 & 27 & 2 & -0.10 & 2 & 25 \\
$\beta_{3}$ & 0.16 & 23 & 7 & 0.05 & 6 & 2 & 0.23 & 28 & 5 \\
$\beta_{4}$ & 0.12 & 40 & 4 & 0.10 & 23 & 2 & 0.12 & 35 & 4 \\
$\beta_{5}$ & 0.22 & 76 & 2 & 0.22 & 59 & 3 & 0.21 & 74 & 2 \\
$\gamma_{1}$ & 0.23 & 14 & 4 & 1.44 & 20 & 7 & 0.28 & 17 & 3 \\
$\gamma_{2}$ & -0.69 & 1 & 24 & -1.55 & 2 & 31 & -0.59 & 2 & 26 \\
\hline \hline
\end{tabular}


Table 3b: Summary results of the estimation - MFHF

\begin{tabular}{ccccccccccc}
\hline \hline & \multicolumn{1}{c}{ MFHF } \\
\cline { 2 - 11 } Period & $2006-2008$ & \multicolumn{1}{c}{$2006-06: 2007$} & \multicolumn{2}{c}{$07: 2007-2008$} \\
$R_{\text {adj }}^{2}$ & \multicolumn{2}{c}{$17.0 \%$} & \multicolumn{2}{c}{$25.4 \%$} & \multicolumn{3}{c}{$25.9 \%$} \\
& mean & $>0$ & $<0$ & mean & $>0$ & $<0$ & mean & $>0$ & $<0$ \\
\hline$\alpha_{5 F-\text { TM }}$ & 1.23 & 2 & 3 & 2.04 & 8 & 2 & 1.05 & 0 & 2 \\
$\beta_{1}$ & 0.03 & 5 & 15 & 0.12 & 13 & 10 & 0.05 & 7 & 13 \\
$\beta_{2}$ & -0.06 & 1 & 3 & 0.08 & 7 & 0 & -0.15 & 2 & 5 \\
$\beta_{3}$ & -0.06 & 2 & 7 & -0.30 & 1 & 13 & 0.06 & 10 & 5 \\
$\beta_{4}$ & -0.01 & 4 & 6 & 0.09 & 8 & 5 & 0.00 & 5 & 5 \\
$\beta_{5}$ & 0.17 & 19 & 1 & 0.21 & 17 & 2 & 0.25 & 15 & 3 \\
$\gamma_{1}$ & 0.20 & 4 & 1 & -5.34 & 4 & 9 & 0.34 & 4 & 1 \\
$\gamma_{2}$ & 0.07 & 4 & 8 & 0.15 & 3 & 3 & 0.11 & 4 & 9 \\
\hline \hline
\end{tabular}


Table 3c: Summary results of the estimation - FoHF

\begin{tabular}{ccccccccccc}
\hline \hline & \multicolumn{1}{c}{ FoHF } \\
\hline Period & $2006-2008$ & \multicolumn{1}{c}{$2006-06: 2007$} & \multicolumn{3}{c}{$07: 2007-2008$} \\
$R_{\text {adj }}^{2}$ & \multicolumn{2}{c}{$25.9 \%$} & \multicolumn{3}{c}{$23.8 \%$} & \multicolumn{2}{c}{$26.2 \%$} \\
& mean & $>0$ & $<0$ & mean & $>0$ & $<0$ & mean & $>0$ & $<0$ \\
\hline$\alpha_{5 F-\mathrm{TM}}$ & 0.77 & 8 & 12 & 6.26 & 42 & 2 & -5.11 & 3 & 45 \\
$\beta_{1}$ & -0.06 & 5 & 69 & -0.13 & 8 & 58 & -0.04 & 4 & 45 \\
$\beta_{2}$ & -0.04 & 2 & 26 & 0.04 & 16 & 2 & -0.07 & 1 & 44 \\
$\beta_{3}$ & 0.08 & 20 & 2 & 0.13 & 20 & 1 & 0.10 & 26 & 3 \\
$\beta_{4}$ & 0.08 & 44 & 1 & 0.10 & 32 & 1 & 0.08 & 35 & 0 \\
$\beta_{5}$ & 0.10 & 88 & 0 & 0.13 & 83 & 0 & 0.09 & 79 & 0 \\
$\gamma_{1}$ & 0.17 & 23 & 7 & 0.29 & 16 & 8 & 0.21 & 26 & 6 \\
$\gamma_{2}$ & -0.47 & 0 & 53 & -0.75 & 7 & 57 & -0.43 & 0 & 44 \\
\hline \hline
\end{tabular}

This table reports the descriptive statistics obtained when applying the multi-factor TreynorMazuy model to the long/short equity hedge funds (LSHF), to the managed futures hedge funds (MFHF) and to the multi-strategy funds of hedge funds (FoHF) for the whole period (6 January 2006 - 26 December 2008), the pre-crisis period (6 January 2006 - 15 June 2007) and the crisis period ( 22 June 2007- 26 December 2008). Weekly data are obtained from Bloomberg. The alpha, betas and gammas estimates are obtained from the multi-factor Treynor-Mazuy regressions with excess returns: $R_{t}-R_{f}=\alpha_{5 F-\mathrm{TM}}+\beta_{1}\left(R_{S P 500, t}-R_{f}\right)+\beta_{2}\left(R_{R u s s 2000, t}-R_{S P 500, t}\right)+\beta_{3} L G B_{t}+\beta_{4}\left(H Y_{t}-\right.$ $\left.L G B_{t}\right)+\beta_{5}\left(R_{E M, t}-R_{f}\right)+\gamma_{1}\left(R_{S P 500, t}-R_{f}\right)^{2}+\gamma_{2}\left(R_{E M, t}-R_{f}\right)^{2}+\varepsilon_{t}$, where $R_{t}$ is the return of the fund for period $t, R_{f}$ is the average 1-month U.S. Treasury Bills rate for the period of study, $R_{S P 500, t}, R_{R u s s 2000, t}, L G B_{t}, H Y_{t}, R_{E M, t}$ are respectively, the returns of the Standard\&Poor's 500 index, the Russell 2000 index, the Barclays U.S. Treasury 7-10 years index, the Bank of America Merrill Lynch U.S. High Yield Master II index, the MSCI emerging markets index, for period $t$. Alphas are in yearly percentage terms. The $R_{\text {adj }}^{2}$ column reports the average regression significance across each sample. The ' $>0$ ' and ' $<0$ ' columns report the percentage of observations that are significantly positive and negative at the $10 \%$ confidence level, respectively. 
Table 4: Analysis of market timing situations

Table 4a: Analysis of market timing situations - LSHF

\begin{tabular}{|c|c|c|c|c|c|c|c|c|c|c|c|}
\hline & & \multicolumn{10}{|c|}{ LSHF } \\
\hline & & \multirow{2}{*}{$\frac{\text { Timing }}{\text { Period }}$} & \multicolumn{3}{|c|}{ Positive } & \multicolumn{3}{|c|}{ Mixed } & \multicolumn{3}{|c|}{ Negative } \\
\hline & & & 06-08 & 06-07 & 07-08 & 06-08 & 06-07 & 07-08 & 06-08 & 06-07 & 07-08 \\
\hline & & $\mathrm{N}$ & 9 & 12 & 11 & 6 & 9 & 8 & 22 & 29 & 31 \\
\hline \multirow[t]{6}{*}{ S\&P 500} & $\gamma_{1}^{+}$ & $\beta_{1}^{+}$ & & 2 & & & 3 & & & & \\
\hline & & $\beta_{1}^{-}$ & 1 & 1 & 1 & 1 & 1 & 1 & & & \\
\hline & & $\beta_{1}^{0}$ & 7 & 8 & 8 & 5 & 5 & 7 & & & \\
\hline & $\gamma_{1}^{-}$ & $\beta_{1}^{+}$ & & & & & & & 1 & 4 & 1 \\
\hline & & $\beta_{1}^{-}$ & & & & & & & 1 & & 1 \\
\hline & & $\beta_{1}^{0}$ & & & & & & & 2 & 3 & 1 \\
\hline \multirow[t]{6}{*}{ MSCI EM } & $\gamma_{2}^{+}$ & $\beta_{2}^{+}$ & & 2 & 1 & & & & & & \\
\hline & & $\beta_{2}^{-}$ & & & & & & & & & \\
\hline & & $\beta_{2}^{0}$ & 1 & & 1 & & & & & & \\
\hline & $\gamma_{2}^{-}$ & $\beta_{2}^{+}$ & & & & 5 & 5 & 8 & 16 & 16 & 17 \\
\hline & & $\beta_{2}^{-}$ & & & & & & & & & \\
\hline & & $\beta_{2}^{0}$ & & & & 1 & 4 & 1 & 2 & 6 & 1 \\
\hline
\end{tabular}


Table 4b: Analysis of market timing situations - MFHF

\begin{tabular}{|c|c|c|c|c|c|c|c|c|c|c|c|}
\hline & & \multirow{3}{*}{$\frac{\text { Timing }}{\text { Period }}$} & \multicolumn{9}{|c|}{ MFHF } \\
\hline & & & \multicolumn{3}{|c|}{ Positive } & \multicolumn{3}{|c|}{ Mixed } & \multicolumn{3}{|c|}{ Negative } \\
\hline & & & 06-08 & $06-07$ & $07-08$ & 06-08 & $06-07$ & $07-08$ & 06-08 & $06-07$ & 07-08 \\
\hline & & $\mathrm{N}$ & 6 & 5 & 5 & 2 & 2 & 3 & 7 & 10 & 7 \\
\hline \multirow[t]{6}{*}{$\mathrm{S} \& \mathrm{P} 500$} & $\gamma_{1}^{+}$ & $\beta_{1}^{+}$ & & & & & & & & & \\
\hline & & $\beta_{1}^{-}$ & & 1 & & 1 & & 1 & & & \\
\hline & & $\beta_{1}^{0}$ & 3 & 1 & 2 & 1 & 2 & 1 & & & \\
\hline & $\gamma_{1}^{-}$ & $\beta_{1}^{+}$ & & & & & & 1 & & 6 & \\
\hline & & $\beta_{1}^{-}$ & & & & & & & & & \\
\hline & & $\beta_{1}^{0}$ & & & & & & & & 3 & \\
\hline \multirow[t]{6}{*}{ MSCI EM } & $\gamma_{2}^{+}$ & $\beta_{2}^{+}$ & & 2 & & & & 1 & & & \\
\hline & & $\beta_{2}^{-}$ & & & & & & & & & \\
\hline & & $\beta_{2}^{0}$ & 3 & 1 & 3 & & & & & & \\
\hline & $\gamma_{2}^{-}$ & $\beta_{2}^{+}$ & & & & 2 & & 1 & 6 & 1 & 6 \\
\hline & & $\beta_{2}^{-}$ & & & & & & & & & \\
\hline & & $\beta_{2}^{0}$ & & & & & 2 & 1 & 1 & & 1 \\
\hline
\end{tabular}


Table 4c: Analysis of market timing situations - FoHF

\begin{tabular}{|c|c|c|c|c|c|c|c|c|c|c|c|}
\hline & & \multicolumn{10}{|c|}{ FoHF } \\
\hline & & \multirow{2}{*}{$\frac{\text { Timing }}{\text { Period }}$} & \multicolumn{3}{|c|}{ Positive } & \multicolumn{3}{|c|}{ Mixed } & \multicolumn{3}{|c|}{ Negative } \\
\hline & & & 06-08 & 06-07 & 07-08 & 06-08 & 06-07 & 07-08 & 06-08 & 06-07 & $07-08$ \\
\hline & & $\mathrm{N}$ & 5 & 10 & 8 & 18 & 13 & 18 & 40 & 51 & 31 \\
\hline \multirow[t]{6}{*}{ S\&P 500} & $\gamma_{1}^{+}$ & $\beta_{1}^{+}$ & 1 & & & & & 1 & & & \\
\hline & & $\beta_{1}^{-}$ & 2 & 4 & 1 & 14 & 5 & 11 & & & \\
\hline & & $\beta_{1}^{0}$ & 2 & 1 & 7 & 4 & 6 & 6 & & & \\
\hline & $\gamma_{1}^{-}$ & $\beta_{1}^{+}$ & & & & & & & 2 & 1 & \\
\hline & & $\beta_{1}^{-}$ & & & & & 1 & & 3 & 3 & 2 \\
\hline & & $\beta_{1}^{0}$ & & & & & 1 & & 3 & 2 & 4 \\
\hline \multirow[t]{6}{*}{ MSCI EM } & $\gamma_{2}^{+}$ & $\beta_{2}^{+}$ & & 1 & & & 2 & & & & \\
\hline & & $\beta_{2}^{-}$ & & & & & & & & & \\
\hline & & $\beta_{2}^{0}$ & & 4 & & & & & & & \\
\hline & $\gamma_{2}^{-}$ & $\beta_{2}^{+}$ & & & & 15 & 11 & 14 & 29 & 33 & 21 \\
\hline & & $\beta_{2}^{-}$ & & & & & & & & & \\
\hline & & $\beta_{2}^{0}$ & & & & 3 & & 4 & 6 & 14 & 5 \\
\hline
\end{tabular}

We distinguish positive market timers (positive timing on one or two markets), negative market timers (negative timing on one or two markets), and mixed market timers (positive timing on one market and negative timing on the other) by counting and matching the significant linear $(\beta)$ and quadratic $(\gamma)$ coefficients for each fund. The minimal significance is set to a level of $10 \%$. 
Table 5: Corrections for market timing

Table 5a: Corrections for market timing - LSHF

\begin{tabular}{|c|c|c|c|c|c|c|c|c|}
\hline \multirow[b]{2}{*}{ Fund } & \multirow[b]{2}{*}{ Period } & \multirow[b]{2}{*}{ Timing } & \multirow[b]{2}{*}{$\mathrm{N}$} & \multicolumn{2}{|c|}{ Linear models } & \multicolumn{3}{|c|}{ Multi-factor TM model } \\
\hline & & & & $\alpha_{4 F}$ & $\alpha_{5 F}$ & $\alpha_{5 F-\mathrm{TM}}$ & adjust. & $\pi_{\mathrm{TM}}^{*}$ \\
\hline \multirow[t]{9}{*}{ LSHF } & 2006-2008 & Positive & 9 & -2.16 & -2.40 & -2.91 & 11.12 & 8.21 \\
\hline & & Mixed & 6 & -9.98 & -9.49 & -2.17 & -8.21 & -10.38 \\
\hline & & Negative & 22 & -11.68 & -11.46 & 1.55 & -17.72 & -16.17 \\
\hline & 2006-06:2007 & Positive & 12 & 8.65 & 6.31 & 2.79 & 14.64 & 17.43 \\
\hline & & Mixed & 9 & 12.99 & 6.46 & 13.12 & -4.99 & 8.13 \\
\hline & & Negative & 29 & 7.25 & 3.88 & 13.15 & -14.56 & -1.40 \\
\hline & 07:2007-2008 & Positive & 11 & -9.98 & -8.64 & -10.06 & 12.82 & 2.76 \\
\hline & & Mixed & 8 & -18.69 & -17.71 & -12.35 & -3.12 & -15.47 \\
\hline & & Negative & 21 & -27.16 & -25.26 & -8.95 & -21.92 & -30.87 \\
\hline
\end{tabular}


Table 5b: Corrections for market timing - MFHF

\begin{tabular}{|c|c|c|c|c|c|c|c|c|}
\hline \multirow[b]{2}{*}{ Fund } & \multirow[b]{2}{*}{ Period } & \multirow[b]{2}{*}{ Timing } & \multirow[b]{2}{*}{$\mathrm{N}$} & \multicolumn{2}{|c|}{ Linear models } & \multicolumn{3}{|c|}{ Multi-factor TM model } \\
\hline & & & & $\alpha_{4 F}$ & $\alpha_{5 F}$ & $\alpha_{5 F-\mathrm{TM}}$ & adjust. & $\pi_{\mathrm{TM}}^{*}$ \\
\hline \multirow[t]{9}{*}{ MFHF } & $2006-2008$ & Positive & 6 & 6.92 & 6.88 & -0.79 & 16.76 & 15.96 \\
\hline & & Mixed & 2 & 7.37 & 3.23 & 6.76 & -8.46 & -1.70 \\
\hline & & Negative & 7 & -9.94 & -9.79 & 1.29 & -16.05 & -14.76 \\
\hline & 2006-06:2007 & Positive & 5 & 0.03 & 1.54 & -7.08 & 18.07 & 10.99 \\
\hline & & Mixed & 2 & 0.92 & 0.70 & -17.57 & 17.67 & 0.10 \\
\hline & & Negative & 10 & 6.29 & -1.82 & 22.38 & -34.50 & -12.12 \\
\hline & 07:2007-2008 & Positive & 5 & 13.42 & 9.79 & -3.73 & 24.32 & 20.59 \\
\hline & & Mixed & 3 & 12.73 & 16.50 & 18.41 & -6.37 & 12.03 \\
\hline & & Negative & 7 & -21.83 & -19.09 & -2.24 & -21.80 & -24.04 \\
\hline
\end{tabular}


Table 5c: Corrections for market timing - FoHF

\begin{tabular}{|c|c|c|c|c|c|c|c|c|}
\hline \multirow[b]{2}{*}{ Fund } & \multirow[b]{2}{*}{ Period } & \multirow[b]{2}{*}{ Timing } & \multirow[b]{2}{*}{$\mathrm{N}$} & \multicolumn{2}{|c|}{ Linear models } & \multicolumn{3}{|c|}{ Multi-factor TM model } \\
\hline & & & & $\alpha_{4 F}$ & $\alpha_{5 F}$ & $\alpha_{5 F-\mathrm{TM}}$ & adjust. & $\pi_{\mathrm{TM}}^{*}$ \\
\hline \multirow[t]{9}{*}{ FoHF } & 2006-2008 & Positive & 5 & 0.75 & -0.07 & -2.06 & 11.03 & 8.97 \\
\hline & & Mixed & 18 & -3.80 & -3.63 & 0.37 & -9.67 & -9.30 \\
\hline & & Negative & 40 & -5.64 & -4.56 & 2.00 & -10.53 & -8.53 \\
\hline & 2006-06:2007 & Positive & 10 & 4.03 & 0.10 & 3.72 & 8.34 & 12.07 \\
\hline & & Mixed & 13 & 2.25 & 0.20 & 1.68 & -2.84 & -1.16 \\
\hline & & Negative & 51 & 4.14 & 3.26 & 8.45 & -10.44 & -1.99 \\
\hline & 07:2007-2008 & Positive & 8 & -6.06 & -3.05 & -6.07 & 15.46 & 9.39 \\
\hline & & Mixed & 18 & -10.72 & -10.48 & -5.05 & -6.92 & -11.97 \\
\hline & & Negative & 31 & -16.84 & -14.58 & -4.16 & -16.17 & -20.33 \\
\hline
\end{tabular}

This table reports the average values (in yearly percentage terms) of fund performance using the Fama-French-Carhart 4 Factor model (4F) and the linear 5 factor model, uncorrected and corrected Treynor and Mazuy (TM) specifications. 


\section{Table 6: Correlation analysis}

Table 6a: Correlation analysis - positive market timers ( $\gamma_{1}$ signif. pos., $\gamma_{2}$ non-signif. $)$

\begin{tabular}{|c|c|c|c|c|c|c|c|c|c|c|c|c|}
\hline \multirow{3}{*}{$\begin{array}{c}\text { Period } \\
\text { N }\end{array}$} & \multicolumn{4}{|c|}{ 2006-2008 } & \multicolumn{4}{|c|}{ 2006-06:2007 } & \multicolumn{4}{|c|}{ 07:2007-2008 } \\
\hline & \multicolumn{4}{|c|}{16} & \multicolumn{4}{|c|}{16} & \multicolumn{4}{|c|}{19} \\
\hline & $\alpha_{4 \mathrm{~F}}$ & $\alpha_{5 \mathrm{~F}}$ & $\alpha_{5 F-\mathrm{TM}}$ & $\pi_{\mathrm{TM}}^{*}$ & $\alpha_{4 \mathrm{~F}}$ & $\alpha_{5 \mathrm{~F}}$ & $\alpha_{5 F-\mathrm{TM}}$ & $\pi_{\mathrm{TM}}^{*}$ & $\alpha_{4 \mathrm{~F}}$ & $\alpha_{5 \mathrm{~F}}$ & $\alpha_{5 F-\mathrm{TM}}$ & $\pi_{\mathrm{TM}}^{*}$ \\
\hline$\alpha_{5 \mathrm{~F}}$ & 0.78 & & & & 0.91 & & & & 0.93 & & & \\
\hline$\alpha_{5 F-\mathrm{TM}}$ & 0.63 & 0.72 & & & 0.81 & 0.90 & & & 0.85 & 0.93 & & \\
\hline$\pi_{\mathrm{TM}}^{*}$ & 0.64 & 0.71 & 0.41 & & 0.72 & 0.72 & 0.65 & & 0.73 & 0.89 & 0.87 & \\
\hline$\gamma_{1}$ & 0.11 & -0.02 & -0.48 & 0.53 & 0.21 & 0.18 & -0.03 & 0.68 & 0.01 & 0.21 & 0.07 & 0.54 \\
\hline
\end{tabular}

Table 6b: Correlation analysis - negative market timers $\left(\gamma_{2}\right.$ signif. neg., $\gamma_{1}$ non-signif. $)$

\begin{tabular}{|c|c|c|c|c|c|c|c|c|c|c|c|c|}
\hline \multirow{3}{*}{$\begin{array}{c}\text { Period } \\
\text { N }\end{array}$} & \multicolumn{4}{|c|}{ 2006-2008 } & \multicolumn{4}{|c|}{ 2006-06:2007 } & \multicolumn{4}{|c|}{ 07:2007-2008 } \\
\hline & \multicolumn{4}{|c|}{60} & \multicolumn{4}{|c|}{68} & \multicolumn{4}{|c|}{50} \\
\hline & $\alpha_{4 \mathrm{~F}}$ & $\alpha_{5 \mathrm{~F}}$ & $\alpha_{5 F-\mathrm{TM}}$ & $\pi_{\mathrm{TM}}^{*}$ & $\alpha_{4 \mathrm{~F}}$ & $\alpha_{5 \mathrm{~F}}$ & $\alpha_{5 F-\mathrm{TM}}$ & $\pi_{\mathrm{TM}}^{*}$ & $\alpha_{4 \mathrm{~F}}$ & $\alpha_{5 \mathrm{~F}}$ & $\alpha_{5 F-\mathrm{TM}}$ & $\pi_{\mathrm{TM}}^{*}$ \\
\hline$\alpha_{5 \mathrm{~F}}$ & 0.94 & & & & 0.91 & & & & 0.93 & & & \\
\hline$\alpha_{5 F-\mathrm{TM}}$ & 0.51 & 0.46 & & & 0.88 & 0.90 & & & 0.84 & 0.94 & & \\
\hline$\pi_{\mathrm{TM}}^{*}$ & 0.80 & 0.88 & 0.28 & & 0.62 & 0.71 & 0.65 & & 0.78 & 0.77 & 0.78 & \\
\hline$\gamma_{2}$ & 0.57 & 0.68 & -0.24 & 0.84 & -0.58 & -0.51 & -0.68 & 0.07 & 0.46 & 0.37 & 0.35 & 0.81 \\
\hline
\end{tabular}

This table reports the linear correlation coefficients between performance measures and the quadratic coefficients in the Treynor and Mazuy (TM) regression $\left(\gamma_{1}\right.$ and $\left.\gamma_{2}\right)$. We distinguish positive market timers and negative market timers. We aggregate the long/short equity hedge funds (LSHF), the managed futures hedge funds (MFHF) and the multi-strategy funds of hedge funds (FoHF) but focus on funds displaying a positive convexity in regard to the US stock market (positive market timers) and funds displaying a negative convexity in regard to the emerging stock market (negative market timers). The minimal significance is set to a level of $10 \%$. 